\title{
An Integrated Approach to Improving Strategic Performance Management in Higher Education: University of Kufa is a model from developing countries
}

\author{
$1^{\text {st }}$ Ahmed Maher Mohammed Ali ${ }^{1}, 2^{\text {nd }}$ Yasir Sahib Malik ${ }^{2}, 3^{\text {rd }}$ Hassnain Kadhem Ojah ${ }^{3}$ \\ \{ ahmedm.fadhil@uokufa.edu.iq ${ }^{1}$, yasirs.abdali@uokufa.edu.iq ${ }^{2}$, \\ hassnink.alshahmani@uokufa.edu.iq ${ }^{3}$ \} \\ ${ }^{1,2,3}$ Faculty of Administration and Economics, University of Kufa, Iraq
}

\begin{abstract}
Improving Strategic Performance Management in the contemporary competitive environment has given way to Higher education to regulate their processes, resources, policies, employees, and systems to Strategic advantages and objectives. The present paper studies the Improving Strategic Performance Management with reference to its development, application, and applicability of Improving Strategic Performance Management in Higher education by literature review. The use of Strategic Performance Management in Higher Education is revealed by a survey of the literature; nevertheless, it must be redefined and tailored to the demands and standards of the institutions. The present trends in Strategic Performance Management in Higher Education are approved and recommended by the review. The theme of emerging research focuses on the Integrated Approach of Strategic Management in improving Higher Education performance, Providing a holistic view, it emphasizes the quality of processes to achieve customer satisfaction in return for achieving quality education. as well as integrating various steps to enable the achievement of the improving Strategic Performance Management in Higher Education. This paper adds to previous value relevance literature and Improving Strategic Performance Management by throwing light on the University of Kufa sector in developing countries.
\end{abstract}

Keywords: Strategic Performance Management, Higher Education, University of Kufa.

\section{Introduction}

In recent years, research on the relationship between Strategic Performance Management (SPM) and Business Units has grown in importance. Many academics assume that (SPM) must explicitly be advantageous to assist business activities to boost competitive advantage and performance [1]. There is evidence that the Integrated Approach behavior of stakeholders, business processes, internal processes, and Strategic performance measurement systems can result in Higher Education organizations Improving Strategic Performance [2].

Although the phrase Strategic Performance Management (SPM) has been around since the beginning, little research has been done on it at universities. It was solely conducted at university about the control system [3], [4]. Following that, strategic costing, strategic planning, control systems, and strategic performance assessment systems [5] were discussed. This is remarkable given that educational reforms began at the close of the twentieth century, and the old management of higher education has become obsolete [6]. Experiential research on (SPM) and performance has taken a contingency approach, with researchers searching for systematic links between certain (SPM) aspects and Improving performance in Higher Education [7]. Even though many countries have implemented the concept of (SPM) on a large scale, it has been accepted and realized that it is not appropriate, and it will be seen through this study how adjustments might aid in the establishment of a strong infrastructure for the future [8], [2]. The purpose of this article is to demonstrate the value of higher education institutions in developing countries, as well as their objectives and strategies for achieving these goals. As a result, they are required to give information on their priorities and resource allocation to determine the extent to which they are fulfilling their social responsibilities in light of their strategic performance [9], [3], [4]. Everyone now wants data and guidance on how to make higher education institutions more effective. As 
a result, higher education institutions compete for money and market share [10]. They are now working to improve the quality of academic staff recruitment, training, as well as the system for rewarding, motivating, and utilizing them. [11]. These factors all contribute to higher education institutions' strategic performance, and as a result of these new needs, there is a greater demand than ever before for an integrated approach to strategic performance management [12], [13]. The research focuses on using the analysis method of the data from previous studies to demonstrate the role of an integrated approach to managing Strategic performance in higher education [14].

\section{Literature Review}

Although much research has been done on the benefits and drawbacks of traditional and modern strategic management, Little is known about their uses and catalysts for developing successful and helpful systems [15]. When reviewing the literature on dis topic, it emerged that there is little interest in managing actual performance along with implementing the human resource management philosophy in Higher Education Institutions [16]. Is this to say that higher education administrators have several options for implementing the Performance Management strategy to be the best in the industry? Or are there other, non-monetary reasons for implementing this method? [17], [3], [4].

An important question that should be asked in the case of Performance Management: If the practices were implemented in the higher education institution, what could be said about the actual results of these practices and the follow-up of these processes? [18]. According to the opinion of a number of specialists, one of the biggest obstacles is the use of performance results and their monitoring after implementation [19]. The problem of performance results is mostly an evaluation from a financial perspective only [20], [9]. So financial metrics showed difficulty in evaluating Performance Management actually in implementing and evaluating Measures of performance management and implementing This is such a unique and novel practice [21]. The autonomy of higher education institutions has been exploited [22]. However, new pressures on the environment, as well as other economic pressures such as worldwide opposition, marketization, and shifting government functions, depict a different picture [23]. They play a critical role in the development of human resources and manpower, which contribute to a country's social and economic growth and strengthen its position in the global economy [24]. To put this into another way, the university's input, in this case, our students and teachers are the processes, and the result is the number of students graduating with quality [10]. Performance management is one of Improving's attributes [3]. Through the effective implementation of Strategic Performance Management [25], this process can be improved and generate better results.

This western approach of Strategic Performance Management [26] can likewise assist developing countries. Higher education, which is a portion of Human Resource Management policies, and other tertiary education services [27] are the two distinct domains in this topic. Higher education produces two types of outputs: high-quality students and research papers produced as a result of teaching input [28]. These institutions are powered by good outputs in the form of graduates and research publications [4], rather than productivity and revenues. Strategic Performance Management (SPM) is a process for generating a shared understanding of what needs to be accomplished and how it should be accomplished, as well as an integrated strategy to developing and managing people to improve individual, team, and organizational performance [16], [15]. It is one of the most important applications in the field of human resource management, and because of its simplicity in the real world, it is easy to implement and control [12]. Higher education institutions must embrace these Strategic Management strategies to stay competitive and address any compliance and accountability issues that may arise [13]. Furthermore, if not followed correctly, (SPM) has been seen as a flaw [26]. When integrated into an organization's fundamental human resource initiatives, these approaches are effective [17]. HRM has been shown to help Strategic Performance Management and the right Human Resource Management policies that can help an employee's performance in studies and research [11]. In reality, there is a strong link between (SPM) and HRM, and it has been discovered that the correct HRM methods can improve current and future performance [9]. This aids the entire approach to the necessary Improving (SPM) model [22]. There are three different models for strategic performance. The first is to use the model to manage institution performance, and the second is to use the model to measure individual employee's Strategic Performance [24]. The third area is concerned with the integration of employee performance with the organization's overall Strategic Performance [29]. Strategic Performance Management, according to research, is a very powerful instrument that cannot be separated from any other management system [27]. It assists line managers in defining responsibilities and managing people most effectively to get the most out of them [10]. Employee stimulation, pleasure, and obligation are the outcomes of excellent project 
management, all of which, at the very least, contribute to superior results from the start [3]. It is critical to introduce (SPM) to Higher Education Institutions because it aids. evaluate performance using supplied metrics and assists in recognizing employee success to reward them as well as provide opportunities for advancement through performance evaluation and feedback [2]. However, for SPM to function correctly at Higher Education Institutions, it must be modified. Some studies [6] offer a unique perspective on (SPM) practice in Higher Education Institutions. Traditional approaches (SPM), for example, are not suitable for Higher Education Institutions, according to a survey [15], [18]. As a result, existing (SPM) systems must be brought into compliance with Higher Education Institutions' duties for a compatible system that allows for progress and modification. These findings are consistent with those of other studies in the field [14]. The focus should be on academic motivation and progress. Furthermore, they assert for specific significant findings for (SPM) in Higher Education Institutions that there is a divide between the rhetoric of (SPM) and the real world at universities, especially in the research [28].

\section{METHODOLOGY ADOPTED}

The study focuses on how to acquire data using this method, and analyze from the research conducted earlier on the role of Strategic Performance Management in higher education from various sources such as scholarly articles, journals, books, online articles, and so on, and considering the constraints related to the realization, the study is focused on using the approach to collect data and analyze from the research conducted earlier on the role of Strategic Performance Management in higher education from various sources such as scholarly articles, journals, books, online articles, and so on. As the authenticity of the study has been verified in past studies, researchers have determined that this form of research is more appropriate for the observationally-based view and provides the objective of recommending distinguished concepts and measures for adoption. . Using the previous studies provided at the time, the analysis approach is assisting in the structure of a stronger point of view. This type of research aids in assessing the role of Strategic Performance Management in an educational system without jeopardizing ethical concerns. Previously, research on the role of higher education institutions in strategic performance management in developed and developing countries was conducted. The study has been focused on making visuals and charts from the output in a wide manner, with no opinions added. The authors stressed the importance of qualitative research and defined models for implementation, and only those were used. In addition, the variables for Strategic Performance Management have been designed to keep the path clear and free of obstructions. the amalgamation of Improving Strategic Performance Management Indicators are grouped into six viewpoints in this approach:

(1) Educational and learning distinction: According to research, learners can only benefit from education if they are given enough assistance and autonomy to make key decisions. Education also has a good impact on successful learning processes, as well as better and more current learning approaches. Improved student projects, courses that are more relevant to industry practices, motivation to conduct research in certain areas, and improved outcomes. Teaching, learner assistance, instructor support, learning materials, curriculum, assessment, feedback, and improvement are all consistently and continually focused on learning.

(2) Scientific research distinction: Members of the faculty and students must participate in research activities at various levels and are obligated to do so in diverse ways at each level. Scientific research in higher education focuses on integrating information at all levels and applying it to educational aims and objectives.

(3) Community participation, environment development, and stakeholders: Educational institutions serve an important role not only in the development of human resources but also in the development of society. It is the key contributor to the development of human resources to meet social requirements, and it must be included in development plans. In terms of stakeholders, educational institutions should play an important role. Encourage international relationships, practical experiences, and training programs to improve the capacity for sustainable development.

(4) Human and material resources: Should be made accessible Books, nonmaterial audio education environment in an academic environment to facilitate education administration, and all forms of related materials used in the learning process to make learning very easy according to the resources in educational institutions in development.

(5) Financial resources: It is expected that distributing cash to institutions with the best performance will achieve a balance in the quality of academic activities by the latter in contrast to the former. This guideline can be used as a motivational principle in Strategic Performance Management. 
(6) Quality and Institutional capacity: To design procedures and requirements for the plan, three layers of quality were required: primary, institutional, and quality-oriented culture. As a result, intellectual, behavioral, and management competencies must be developed. It necessitates creating awareness about the need of obtaining excellence. As a result, to achieve true educational quality and institutional capability, the following factors must be considered:

- The objectives of the educational performance, the qualifications level, and the curricula;

- The competence and qualifications of the teaching staff, the study environment, and the technical assistant staff.

- The independent assessment of, on the one hand, the educational and research activity and, on the other hand, the students' results.

According to Integrated Approach to Improving Strategic Performance Management, Chancellors' staff were interviewed and Vice-Chancellors to managers on the front lines. the data collected was linked with the Integrated Approach to Improving (SPM). It was found out in the research that the University of Kufa tends to adopt a Central financial and a more administrative-based strategy that focuses on the evaluation of performance traditional instead of the Strategic Performance Management stewardship approach. There is political pressure on Iraqi universities to abide by laws traditional, they could not handle the pressure, therefore it tries to remain within the global ranking of educational institutions in developed countries. Short-term goals are more important, which can jeopardize research excellence and do not align with Higher Education Institutions' long-term goals of providing knowledge for society. Kufa University operates in a context characterized by Weak competitiveness as a result of the public financing system that allocates resources, not based on performance, in other words, the performance of each the university is yearly assessed by The Ministry of Higher Education and Scientific Research. which, subsequently, distributes the public funds to Unfairly. Such a mechanism is based on a Lack of merit principle of resource allocation and, at the same time, its application encourages a performance constancy among all national educational institutions in terms of education quality, research output, and management efficiency. These institutions' research outputs are being held back by the loss of vital education professionals. Furthermore, it limits the quality of instruction provided in the facilities. All of these significant challenges, both for improving outputs and for further growing their staff and policies, exist in the higher education scene of developing countries.

\section{CONCLUSION}

In Higher Education Institutions, the notion of (SPM) is present. However, it must be part of an Integrated Approach to Improving Higher Education Institutions' Vision. Traditional performance management and strategic performance management must be understood by higher education institutions. However, both of these phrases are frequently used interchangeably. Traditional performance management can be seen as a component of Strategic Performance Management systems. Higher education institutions must establish (SPM) methods to improve teacher and student performance by aligning objectives and goals with educational strategic goals. This will be an integrated approach to improving the overall performance of educational institutions so that they can achieve their goals. Strategic performance management at educational institutions must consider the performance of all members of the organization. This covers performances by faculty members as well as administration. The attention, however, Members of the academic and administrative communities should be treated equally.

The most essential indications for Strategic Performance Management, on the other hand, should be the same. The presence of a well-functioning Quality Assurance Department in educational institutions can be extremely beneficial to Higher Education in terms of implementing and designing an effective (SPM) for reviewing and saving results records. Universities should make use of emerging approaches to improve strategic performance management, such as a $360^{\circ}$ assessment and the balanced scorecard, as evidenced by the research. In the context of Higher Education, these strategies of an integrated approach to (SPM) are advised to be used. Furthermore, the results of an integrated approach (SPM) should be used, and faculty members should be satisfied, committed, and motivated, as well as assist the university in understanding job strategic performance through metrics and recognized by correct and deductive feedback.

In conclusion, it was also noted that the central financial and administrative-based method does not work effectively and that the oversight approach is more appropriate. This, however, does not make things any easier to grasp, as professional staff and faculty members always prefer a strategic 
performance management system that is more oriented toward targets and has a clear measuring technique. Most proponents of the specified approach deemed strategic performance feedback and approach certainty to be the most important factors to consider. However, in a world where knowledge and research-creation are valued, this is not the case. As a result, a number of authors have proposed the hybrid Integrated approach as the best strategic performance management system for higher education.

The strengths of both the central financial and administrative-based approach and the monitoring approach will become part of the ideology, giving universities a clear choice. The central financial and administrative strategy gives clarity, but the monitoring method promotes confidence. The university's knowledge habit process will be unaffected, and the personnel will be at ease because the Integrated method will work for their well-being and ensure high-quality long-term strategic performance from their end as well. Iraqi universities are currently compelled to use a central financial and administrative-based method to implement performance management, but with a clear path laid out, it is more probable that a hybrid Integrated approach will prove to be the best option for them.

Strategic performance management should have been a coordinated multilateral effort that drew on the expertise and experiences of both academics and support staff and went beyond typical higher education criteria. With the ultimate goal of being fruitful, the improvement of these perplexing systems must draw on the abilities of management, support, and faculty members. The findings also suggested that traditional commercial approaches to strategic performance management would not work in higher education. As a result, existing performance management methodologies and models should be customized to higher education institutions' visions, with the Integrated approach, which considers a process of institutional reform and systemic change, gradually expanding.

\section{REFERENCES}

[1] Samantha Evans, A. P. (2017). What are the consequences of a managerial approach to union renewal for union behavior? A case study of USDAW, Employee Relations, 39, 1, 2.

[2] Soledad Moya, D. P.-P. (2015). Performance-based Incentives and the Behavior of Accounting Academics: Responding to Changes, Accounting Education,24, 3, 208.

[3] Toke Bjerregaard, C. J. (2014). Organizational Responses to Contending Institutional Logics: The Moderating Effect of Group Dynamics, British Journal of Management, 25, 4, 651.

[4] Ramunè Kasperavičiūtė-Černiauskienė, D. S. (2016). The adoption of ISO 9001 standard within higher education institutions in Lithuania: innovation diffusion approach, Total Quality Management \& Business Excellence, 1.

[5] Denise Thursfield, K. G. (2016). Exploring performance management in four UK trade unions, Employee Relations, $38,5,789$.

[6] Jardioui, Meriam, Patrizia Garengo, and Semma El Alami. (2017). The impact of organizational culture on performance measurement system design, implementation and use: Evidence from Moroccan SMEs. Paper presented at IFIP International Conference on Advances in Production Management Systems, Hamburg, Germany, September 3-7; Cham: Springer.

[7] Kotkova Striteska, Michaela, and Viktor Prokop. (2020). Dynamic Innovation Strategy Model in Practice of Innovation Leaders and Followers in CEE Countries-A Prerequisite for Building Innovative Ecosystems. Sustainability 12: 3918.

[8] Nordiawan, Deddi, Eko Prasodjo, and Sudarsono Hardjosoekarto. (2017). Reconstruction of performance-driven culture: Application of soft systems methodology at East Java Province, Indonesia. Paper presented at 16th European Conference on Research Methodology for Business and Management Studies, Dublin, Ireland, June 22-23; Dublin: Academic Conferences and Publishing International Limited, pp. 277-86.

[9] Prokop, Viktor, Samuel Amponsah Odei, and Jan Stejskal. (2018). Propellants of University-Industry-Government synergy: Comparative study of Czech and Slovak manufacturing industries. Ekonomický `casopis SAV 66: 9871001.

[10] Smith, Marisa, and Umit S. Bititci. (2017). Interplay between performance measurement and management, employee engagement and performance. International Journal of Operations \& Production Management 37: 1207-28. Striteska, Michaela, David Zapletal, and Lucie Jelínková. (2016). Performance management systems in czech companies: Findings from a questionnaire survey. E+M. Economics and Management 4: 44-55.

[11] Samantha Evans, A. P. (2017). What are the consequences of a managerial approach to union renewal for union behavior? A case study of USDAW, Employee Relations, 39, 1, 2.

[12] Muhammad Tanveer, and Asif Mahbub Karim. (2018). Higher Education Institutions and the Performance Management. Library Philosophy and Practice, e-journal, at University of Nebraska-Lincoln,1;23.

[13] Elizabeth Bates, L. K. (2014). Exploring the Impact of the Increased Tuition Fees on Academic Staffs' Experiences in Post-92 Universities: A Small-Scale Qualitative Study, Education Sciences,4, 4, 229.

[14] Achim Krausert. (2017). HR differentiation between professional and managerial employees: Broadening and integrating theoretical perspectives, Human Resource Management Review, 27,3, 442. 
[15] Adelien Decramer, C. S. (2013). Employee performance management culture and system features in higher education: relationship with employee performance management satisfaction, The International Journal of Human Resource Management 24, 2, 352.

[16] Adelien Decramer, M. A. (2015). Does performance management affect nurses' well-being? Evaluation and Program Planning, 49, 98.

[17] Adelien Decramer, S. G. (2013). The impact of internationalization on volume and quality of scholarly publication performance, Public Money \& Management, 33, 2, 111.

[18] Nieves Arranz, F. U. (2016). The effect of curricular and extracurricular activities on university students' entrepreneurial intention and competences, Studies in Higher Education, 1.

[19] Melinde Coetzee, J. M.-M. (2014). Human resource practices as predictors of engineering staff's organizational commitment, SA Journal of Human Resource Management,12, 1.

[20] Kamel Mellahi, J. G. (2016). Performance management practices within emerging market multinational enterprises: the case of Brazilian multinationals, The International Journal of Human Resource Management, 27, 8, 876.

[21] Layland, A., \& Redding, S. (2020). Strategic performance management with a communication lens. Rockville, MD: National Comprehensive Center at Westat, $f$ this publication can be downloaded from https://www.compcenternetwork.org.

[22] Layland, A., \& Redding, S. (2017). Casting a statewide strategic performance net: Interlaced data and responsive supports. San Antonio, TX: Building State Capacity and Productivity Center.

[23] Lewis, L. (2019). Organizational change: Creating change through strategic communication. Hoboken, NJ: John Wiley \& Sons.

[24] Redding, S., \& Layland, A. (2017). Strategic performance for your branch: Organizing people and their work in an LEA or SEA Division or strand. San Antonio, TX: Building State Capacity and Productivity Center.

[25] Zavadsky, H., Berry, T., \& Savage, T. (2017). BSCP center strategic communications toolbox. San Antonio, TX: Building State Capacity and Productivity Center at Westat.

[26] Michaela Kotkova Striteska \& David Zapletal. (2020). The Role of Corporate Culture in Performance Measurement and Management Systems, international journal of Financial Studies, 2;12.

[27] Gochhayat, Jyotiranjan, Vijai N. Giri, and Damodar Suar. (2017). Influence of organizational culture on organizational effectiveness: The mediating role of organizational communication. Global Business Review 18: 691-702.

[28] Halaskova, Martina, Renata Halaskova, and Viktor Prokop. (2018). Evaluation of efficiency in selected areas of public services in European Union countries. Sustainability 10: 4592

[29] Kamel Mellahi, J. G. (2016). Performance management practices within emerging market multinational enterprises: the case of Brazilian multinationals, The International Journal of Human Resource Management, 27, 8, 876. 